\title{
Performance Evaluation of a Solar Powered Air Dryer for White Oyster Mushroom Drying
}

\author{
A. G. M. B. MUSTAYEN ${ }^{1}$, MOHAMMAD MAHBUBUR RAHMAN ${ }^{1}, \mathrm{~S}_{\text {MEKHILEF }}{ }^{1}$, and R. SAIDUR ${ }^{2}$ \\ ${ }^{1}$ Power Electronics and Renewable Energy Research Laboratory (PEARL), Department of Electrical Engineering, University of Malaya, \\ Kuala Lumpur, Malaysia \\ ${ }^{2}$ King Fahd University of Petroleum and Minerals (KFUPM), Dhahran, Saudi Arabia
}

In this paper, the performance of an efficient solar dryer was experimentally investigated and tested. The dryer was configured for harvesting maximum rate of solar radiation by having a longer drying period. The three axial flow fans provide the air inlet which can accelerate the drying rate. An electrical backup was also used for continuous drying process. Final moisture content and cabinet temperature (CT) were recorded and compared to the open sun drying and oven drying process. White oyster mushroom was dried at $50^{\circ} \mathrm{C}$ to $60^{\circ} \mathrm{C}$ and the desired moisture content of $7.97 \%$ has been achieved without affecting the product color. Activation energy, product output rate (POR), evaporation rate have been calculated. Shrinkage of drying mushroom was analyzed at different temperatures. The important climatic variables such as solar radiation, temperature and relative humidity are the main factors that affect the drying rate constant $(k)$. Final output indicates that the quality of dried product in solar powered air dryer was competitive with the branded products available in the market. This drying system can be used for a wide range of agricultural products.

Keywords: Solar powered air elryer, Shrinkage, Final moisture constant, White oyster mushroom

\section{Introduction}

Moisture removal from food materials by thermal drying is an integral part of preservation processing. Drying is essentially a process for simultaneous heat and mass transfer operations. The drying system takes place in two stages. In the first stage the drying samples get heat from the solar radiation for evaporation of surface water and in the second stage the surroundings air flow is used to remove the moisture vapor from the drying materials.

Many researchers stated the design and performance of various types of solar dryers. Some of them designed and constructed multi-purpose transparent systems which were powered by air flow and PV modules (Schirmer et al. 1996). In the drying process, the sample of the dried products gaining energy from both of hot air and direct solar radiation. In a solar drying system most effective factor is the inside cabinet temperature (CT) (AlJuamily, Khalifa, Yassen 2007). In terms of color, flavor and texture the quality of the solar drying products is better than the quality of the traditional drying products. Drying temperature has an effect on the brightness, hardness and springiness of the samples (Kotwaliwale, Bakane, Verma 2007). In a cabinet type convective solar dryer, the maximum solar radiation

Address correspondence to S. Mekhilef, Power Electronics and Renewable Energy Research Laboratory (PEARL), Department of Electrical Engineering, University of Malaya, 50603 Kuala Lumpur, Malaysia.E-mail: saad@um.edu.my

Color versions of one or more of the figures in the article can be found online at www.tandfonline.com/ljge. has been absorbed and the discoloration problem has been prevented due to irradiation through direct sunlight. Solar tunnel dryer consists UV stabilized plastic covered flat plate collector which maintain the quality of products to meet with international market standard (Sreekumar, Manikantan, Vijayakumar 2008; Bala, Morshed, Rahman 2009). Tracking the sun allowing a faster rate of drying did not offer a significant advantage in terms of length of drying time duration (Mwithiga and Kigo 2006). The market value of freeze drying products is high but for high cost it has some limits to use largely in the industrial sectors (Ciurzyńska and Lenart 2011). Freeze drying is the process of dehydration by sublimation of product (Ratti 2001). Open sun drying is costly but discontinuous process (Juang et al. 1984). During the freezing and the solar drying process, some components have restrained in the solar drying system over freeze drying (Carpenter et al. 1994). In the microwave drying system, low air velocity performed for drying operation and it is possible to reduce the drying time. In comparison with other drying systems solar drying is more beneficial in sub-tropical countries (Funebo and Ohlsson 1998). Rehydration system in microwave vacuum drying was significantly affected on the system pressure, microwave power level but in the solar dying process the affect is very negligible (Giri and Prasad 2007).

For the nutritional value, delicacy and flavor, mushrooms have a high commercial demand. Mushrooms are known as a rich in vitamins, protein content, amino acids. They are also used as a meat substitutes and as a protein source in vegan diets (Ghorai et al. 2009). Pleurotus app., commonly known as the oyster mushroom which are two types such as white oyster mushroom and grey oyster mushroom) among all the most popular 
cultivated edible fungi worldwide due to its medicinal properties, vigorous growth and undemanding cultivations conditions (Gregori, Švagelj, Pohleven 2007). For high moisture content and rich nutrients, oyster mushrooms spoil easily and quickly. After harvesting, the self-life of fresh mushrooms is only about $22 \mathrm{hr}$ at ambient temperature. In refrigerator storage system, it can be stored $6-9$ days. But after drying in convective solar dryer, its preservation time is more than 6 months.

After cultivating agricultural products, it has to undergo a number of processes which may cause various changes in physi$\mathrm{cal}$, chemical and biological characteristics. If the agro-products will not be preserved in a good method, the quality of the product will go under minimum standard range. Among all types of drying methods, the open sun drying system produces unhygienic and low quality drying products. It takes long time, color changes due to overheating, losses in flavor and also decreases the dehydration abilities. Freeze and microwave drying for medicinal use basically peptide-based drugs, but these systems need electrical energy and also require long time. On the other hand, mechanical drying process requires fossil fuels as well as diesel, oil etc. Though drying is an energy conservation process, in case of economical question and suitability the freeze, micro-oven and mechanical drying are not suitable.

Dehydration of agricultural products by hot air flow and the passage of an air mass around a product represent a complex thermal process where unsteady heat and moisture transfer occur simultaneously. Heat and moisture transfer rates are related to the air velocity and the temperature of the circulating drying air (Sahin and Dincer 2002). For faster moisture absorption of dried product need higher dehydration temperature (Tripathy and Kumar 2009). From thousands of years, the solar radiation has been used to dry food. In traditional open sun drying method, the drying rate is dependent on some external parameters i.e. wind velocity, solar radiation, ambient temperature, relative humidity and also some internal parameters such as initial moisture content of samples, type of product etc. (Jain and Tiwari 2003). Due to lack of sufficient preservation methods, farmers have to spread

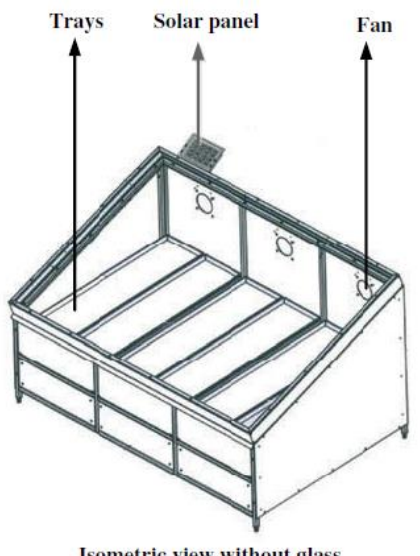

Isometric view without glass

Fig. 1. Schematic diagram of solar powered air dryer. the product in thin layer on paved ground or on mats where this is exposed to sun and wind. The solar drying systems also improve the quality of products, minimize wastes. This drying technology is co-friendly (Prasad, Prasad, Vijay 2006; Prakash and Kumar 2013). In recent years some studies have been reported on the drying of mushrooms (Giri and Prasad 2007; Shukla and Singh 2007).

This paper presents the experimental studies of the solar drying of mushroom using solar powered air dryer. The objective of this study is to evaluate the performance of solar powered air dryer and analyze the different drying characteristics. For the uniform temperature and low air velocity this dryer can produce the maximum possible solar energy. The quality of the solar drying sample has been compared with the open sun drying and oven drying method and carried out a significant analysis on temperature, moisture content, color and shrinkage effect.

\section{Description of the Solar Powered Air Drying System}

A solar powered air dryer (SDM-50) was selected for this experiment. Two methods were used to operate the dryer. Solar mode involves to utilization of the solar radiation for producing heat to dry the products. A 20 Watt solar panel is connected on the top back of the dryer for collecting radiations. Three fans were used for air blowing. Electrical mode is a standby mode which utilizes artificial heating by using coils connected to a backup electricity supply. The electrical mode is used in case of insufficient sunlight or cloudy sky. A duel channel digital temperature indicator (EQUINOX-T-1000-2CH) is provided with two sensors for measuring ambient temperature and $\mathrm{CT}$, respectively. The isometric view of the solar powered air dryer is shown in Figure 1 and the sectional view of solar powered air dryer is shown in Figure 2.

The total drying system consist a DC adapter $(12 \mathrm{~V}, 2 \mathrm{~A})$, an AC $220 \mathrm{~V}$ voltmeter, a thermostat cutoff indicator, three heaters and an inbuilt AC-DC converter. Here a 20V DC electrical flow has been changed to a $110 \mathrm{~V}$ AC electrical flow for operating the dryer heater, the blower, the compressor and sensors. The

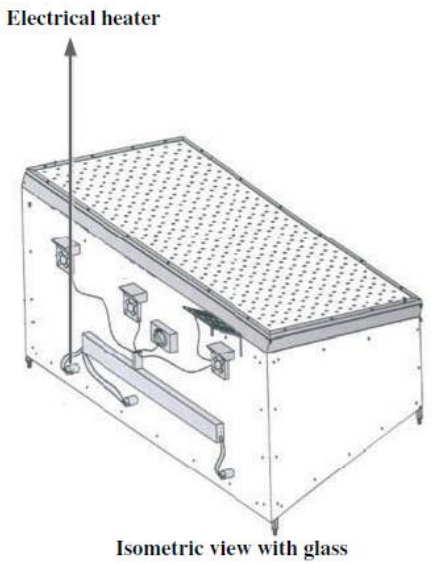



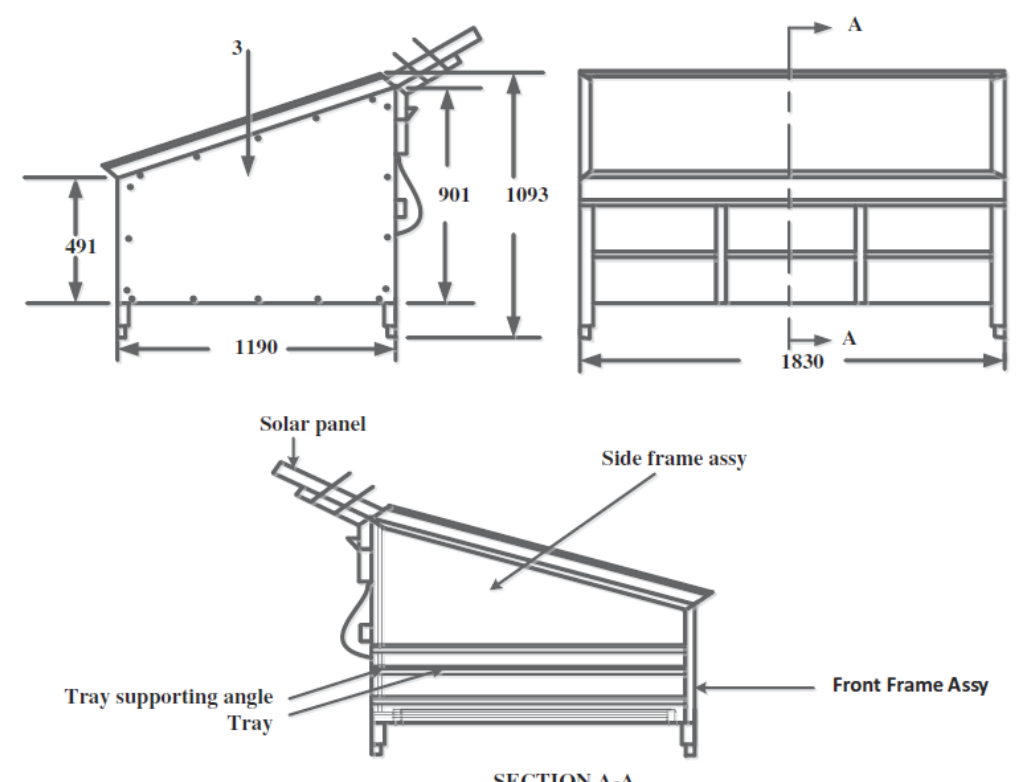

SECTION A-A

Fig. 2. Sectional views of solar powered air dryer in different positions.

dryer is rain, dust, insect and rodent proof due to fixation of EPDM gaskets and can be easily replaced in case of damage. Minimal thermal loss occurred due to direct penetration of solar radiation into the cabinet through the glass window. Drying process occurred under the most hygienic conditions and the dried products meet the international standards quality.

\section{The Components of the Dryer}

\section{The cabinet}

The construction of the solar powered air dryer involves a metal cabinet made of aluminum alloy with a glass window on the top. The cabinet of the dryer is $1828.8 \mathrm{~mm}$ long, $1219.2 \mathrm{~mm}$ wide and $1371.6 \mathrm{~mm}$ high. The dryer has an electrical backup that is $3.6 \mathrm{~kW}$. The inside of cabinet is provided with stainless steel internal structure and 12 stainless steel trays to place the samples to be dried. The whole cabinet of the dryer is made by aluminum. The solar radiation passes through the transparent glass window which is located on the top of the cabinet and it is oriented to south with a title angle equal to the latitude to collect maximum radiation. This drying system allows exposure of the product to solar radiation passing through its high transmittance glass which put on top, as an important feature for obtaining high quality dried products. The cabinet is modular in nature and it is made of anti-corrosive materials to meet the varying sizes and capacities. An UV radiation can work as an anti-bacteria and vitamin inducer factor. Color, taste and texture of samples can be maintained as in the original. It preserves the high amount of nutritional components namely vitamins, protein etc.

\section{System dehydration accessories}

In this drying process, three axial forced fans provide for producing sufficient hot air to evaporate of water from the surface of the samples. Water vapor diffuses through a boundary film of air and is carried away by the moving air. In this solar powered air dryer the $\mathrm{CT}$ is maintained $48^{\circ} \mathrm{C}$ to $60^{\circ} \mathrm{C}$ on clean sunny days while the ambient temperature arise between $24^{\circ} \mathrm{C}$ and $35^{\circ} \mathrm{C}$.

Sensors

A duel channel digital temperature indicator (EQUINOX-T$1000-2 \mathrm{CH}$ ) is provided with two sensor ports for measuring ambient temperature and CT, respectively. A control box is connected with the sensors. The box is also connected to a power source. It displays ambient temperature as well as CT at the same time. It should be operated at $240 \mathrm{~V}$ AC. A hygro-transmeter was used to measure the humidity. The load cell display shows the weight change of samples inside the drying cabinet. Default temperature gauge is used to monitor and control the desired temperature. The moisture control in the samples is achieved by the regulation of the drying time based on the intensity of the solar radiation.

\section{Methods and Materials}

Analysis of Drying Parameters

Drying rate constant

The drying rate constant $(k)$ is an important parameter to accelerate the rate of drying and water remove from the sample. It was 
derived by fitting moisture content and the drying time. The mathematical equation form of the drying rate constant is,

$$
e^{-k t}=\frac{M_{\mathrm{gom}}-M_{f}}{\mathrm{M}_{\mathrm{i}}-M_{f}}
$$

where $M_{\text {gom }}$ is the moisture content of the white oyster mushroom sample (d.b.), $M_{f}$ is the sample's final moisture content (d.b.), $M_{i}$ is the initial moisture content (d.b.), $t$ is time from placement of sample in to the drying cabinet. The only changing factors that significantly contributed to faster drying, as measured by increasing $k$ values, where an increase in drying temperature and a decrease in relative humidity of drying air (Weller and Bunn 1993).

Product output rate and evaporation rate

During the experiment, some dependent variables were considered such as product output rate (POR), evaporation rate (ER) and kernel cracking $(\mathrm{KC})$. POR is an indicator of the dryer working capacity and evaporate rate (ER) is a quality index of the drying kinetics. In this work, the kernel cracking after drying was determined by using scanning electron microscope and described letter. From Eqs 2 and 3, POR and ER values were calculated.

$$
\begin{gathered}
P O R=\frac{m_{d}}{A_{b} \times t} \\
E R=\frac{m_{v}}{A_{b} \times t}
\end{gathered}
$$

where $m_{d}$ is the mass of the dried products, $m_{v}$ is the mass of the vaporized moisture $(\mathrm{g}), A_{b}$ is the area of the dryer chamber $\left(\mathrm{m}^{-\hat{2}}\right)$, and $t$ is drying time (s).

\section{Activation energy}

The activation energy is interpreted as the minimum energy required to break water-solid or water-water interactions and to move the water molecules from one point to another in the solid during drying time. The activation energy which required for drying is calculated using the Arrhenius equation as follows (Jena and Sahoo 2013),

$$
\operatorname{In}\left(D_{\text {eff }}\right)=\operatorname{In}\left(D_{o}\right)-\frac{E_{a}}{R} \frac{1}{T}
$$

$\operatorname{In}\left(D_{\text {eff }}\right)$ is the constant, $E_{a}$ is the activation energy $(\mathrm{kJ} / \mathrm{mol})$, Ris the universal gas constant $(8.314 \mathrm{~kJ} /(\mathrm{mol} \mathrm{K}))$, and $T$ is the absolute temperature $(\mathrm{K})$.

\section{Sample Preparation}

Fresh sporocarps of $P$. pulmonarius which known as white oyster mushroom purchased from a local mushroom farm, Ganofarm Sdn Bhd, Malaysia and kept in cold storage at 7-9 ${ }^{\circ} \mathrm{C}$. Mushrooms were rinsed thoroughly for removing the dust and rated by size to eradicate the variations regarding apparent surface area. The sample was prepared in a hygienic procedure Before inserting the sample into the dryer cabinet, the samples were weighted instantaneously. Weights of samples were measured every $45 \mathrm{~min}$ interval with a digital balance and weight loss has been recorded. The procedure was repeated again and again until the final moisture content was not reached minimum level. This corresponds to drying time of around 12 to $13 \mathrm{hr}$ depend on solar radiation, wind velocity and ambient temperature.

\section{Drying Methods}

Three types of drying process were used in this experiment. At $45^{\circ} \mathrm{C}$ constant temperature, oven drying process occurred. The outdoor drying under open air rising $24^{\circ} \mathrm{C}$ to $35^{\circ} \mathrm{C}$ and the solar drying with solar powered air dryer occurred when the temperature is rising $48^{\circ} \mathrm{C}$ to $62^{\circ} \mathrm{C}$. The drying process was over when the minimum moisture content of mushrooms reached $7.97 \%$. Initial moisture content of the samples is determined as percentage by weight difference with a moisture analyzer. During drying period, the weight is taken one hour duration.

The average non-dimensional moisture ratio of experimental samples expressed by the Eq. 5 which is given below,

$$
M R=\frac{M-M_{e}}{M_{o}-M_{e}}
$$

$M R$ is the dimensionless moisture ratio, $M_{0}$ and $M_{e}$ is the initial and final moisture content on dry basis, respectively (Şevik et al. 2013).

Initial moisture content of white oyster mushroom was calculated by following equation,

$$
M C_{d b}=\frac{M_{i}-M_{d}}{M_{d}} \times 100
$$

\section{Environmental Condition}

The experiment was carried out in August to October (2013) at the University of Malaya, Kuala Lumpur, Malaysia. Relative humidity and the temperature were measured during the experiment by using a temperature humidity measurement instrument $\left(-40^{\circ} \mathrm{C}-90^{\circ} \mathrm{C}, 0-100 \% \mathrm{RH}\right)$ and recoded. The graph of relative humidity (RH) and the environmental temperature (ET) are shown in Figure 3.

\section{Experimental Setup}

The drying of agricultural products depends on the temperature and humidity of the surroundings. Drying by traditional hot air under open sun, may prolong the drying time due to its intake of high humid air. But increasing the drying temperature seems necessary to shorten the drying time. On the other hand, the controlling temperature and rates of water removal is critical to gaining optimal product quality during drying in solar dryer.

The experimental setup is shown in Figure 4. During the experiment, a duel channel digital temperature indicator was provided with two sensors for taking temperature. One sensor was used for measuring ambient temperature (AT) and other sensor was used for CT of dryer. It was operated at $240 \mathrm{~V}$ AC. Connect the control box with sensor earmarked on the back side and it displayed ambient temperature as well as CT at the same time. The ambient temperature (AT) and CT of the drying period are shown in Figure 5.

\section{Link to Full-Text Articles :}

